\title{
APOE genotypes and dyslipidemias in a sample of the Portuguese population
}

\author{
Maria Odete Rodrigues ${ }^{1}$, Aidil Fonseca ${ }^{1, *}$, \\ Carlos Matias Dias ${ }^{2}$, Isabel Albergaria ${ }^{1}$, Gisela \\ Martins ${ }^{1}$, Maria Liseta Alpendre ${ }^{1}$ and Maria do \\ Carmo Martins ${ }^{1}$ \\ ${ }^{1}$ Centro de Biopatologia, \\ ${ }^{2}$ Observatório Nacional de Saúde, \\ Centro de Epidemiologia e Bioestatística, Instituto \\ Nacional de Saúde, Lisboa, Portugal
}

\begin{abstract}
The objective of this work was to study the distribution of apolipoprotein $\mathrm{E}(A P O E)$ genotypes in a sample of the Portuguese population, and its association with the dyslipidemias observed. Study participants were healthy users of local Public Health Laboratories in six regions of mainland Portugal (Porto, Vila Real, Viseu, Lisboa, Portalegre and Faro). A total of 779 men and 1153 women aged 15-74 years agreed to participate. Fasting lipid levels and APOE genotypes were determined centrally at the National Institute of Health in Lisboa. The frequency distribution of $A P O E$ alleles was: $\varepsilon 2=5.3 \%, \varepsilon 3=84.9 \%$ and $\varepsilon 4=9.8 \%$. Dyslipidemias were present in $66.6 \%$ of men and $60.7 \%$ of women. Comparison of APOE genotypes and relative allele frequencies showed that in dyslipidemic compared to normolipidemic subjects, the $\varepsilon 4$ allele was more frequent in both sexes, although in a more pronounced way in men than in women due to higher frequencies of $\varepsilon 3 / \varepsilon 4$ and $\varepsilon 4 / \varepsilon 4$ genotypes. The known association of the $\varepsilon 4$ allele with high cholesterol levels, the association of the $\varepsilon 2$ allele with low cholesterol levels, and the association of the $\varepsilon 2$ allele with high levels of triglycerides and low levels of high-density lipoprotein-cholesterol were confirmed in this study.
\end{abstract}

Keywords: $A P O E$ genotypes; cardiovascular diseases; dyslipidemias; Portuguese regions.

\section{Introduction}

The apolipopotein $\mathrm{E}(A P O E)$ gene locus is polymorphic and three common alleles, $\varepsilon 2, \varepsilon 3, \varepsilon 4$ are inherited in a codominant way. These encode isoforms of the corresponding plasma proteins, E2, E3, and E4, which can occur in six different phenotypes. The E3/3 phenotype is the commonest in different populations.

*Corresponding author: Aidil Fonseca, Instituto Nacional de Saúde Dr. Ricardo Jorge, Av. Padre Cruz, 1649-016 Lisboa, Portugal

Phone: +351-21-7519-444, Fax: + 351-21-752-6400,

E-mail: aidil.fonseca@insa.min-saude.pt
These isoforms differ by a single amino acid substitution and, consequently, have different binding affinities for the four known apoE receptors. Specific literature on the complex biochemical aspects of the mechanisms involved is abundant (1-3).

The isoforms are related to amino acid substitutions in E2, E3, and E4 that influence their ionic binding to specific receptor domains and kinetics (4). Through this principal mechanism, apoE influences the metabolism of atherogenic lipoproteins - apoBcontaining lipoproteins - and the reverse cholesterol transport (5).

Compared with $\varepsilon 3$, the $\varepsilon 2$ allele is frequently associated with low levels of total and low-density lipoprotein-cholesterol (LDL-C) and the opposite typically occurs with the $\varepsilon 4$ allele. Nevertheless, the $\varepsilon 2$ allele is also associated with a tendency towards higher triglyceride levels (6). APOE genotypes may thus influence mean plasma lipid values and the frequency of various types of dyslipidemias, which are considered important risk factors for the development of atherosclerosis and cardiovascular diseases (CVD) $(7,8)$.

The Portuguese population is characterized by high rates of dyslipidemias and CVD, but not much is known about the influence of $A P O E$ genotypes on these situations (9-12).

The aim of this work was to study the distribution of $A P O E$ genotypes in the population of six regions of mainland Portugal and to relate them to the dyslipidemias observed.

\section{Materials and methods}

\section{Sampling locations and subjects}

Six regions across mainland Portugal were selected as sampling locations: Porto, Vila Real and Viseu in the north; Lisboa and Portalegre in the center; and Faro in the South.

Blood samples were collected from users of the six local Public Health Laboratories attending for health control checks, who were randomly invited to participate every day during 6 months.

The sample population distribution was: $24.9 \%$ in Porto, $27.6 \%$ in Lisbon, the biggest cities, $12.8 \%$ in Vila Real, $12.7 \%$ in Viseu, $11.7 \%$ in Portalegre and $10.3 \%$ in Faro, totaling 779 men and 1153 women, aged $15-74$ years. None of them reported taking hypolipidemic drugs or oral contraceptives. All subjects gave their written informed consent to participate and the Ethics Committee at the National Institute of Health (NIH) approved the study.

\section{Blood samples}

Blood samples were collected by venepuncture, with subjects in a sitting position after overnight fasting. Two vacutainer tubes were used, one with EDTA for DNA extraction 
Table 1 Lipid characteristics of normolipidemic and dyslipidemic participants.

\begin{tabular}{lll}
\hline Normolipidemic subjects & Male & Female \\
& $\mathrm{n}=260(33.38 \%)$ & $\mathrm{n}=453(39.29 \%)$ \\
\hline Age, years & $38.7 \pm 17.6$ & $37.5 \pm 14.5$ \\
Cholesterol, mmol/L & $4.08 \pm 0.58$ & $4.20 \pm 0.55$ \\
Triglycerides, mmol/L & $0.96 \pm 0.29$ & $0.95 \pm 0.32$ \\
HDL-C, mmol/L & $1.27 \pm 0.19$ & $1.46 \pm 0.27$ \\
LDL-C, mmol/L & $2.39 \pm 0.52$ & $2.33 \pm 0.50$ \\
ApoA1, g/L & $1.39 \pm 0.21$ & $1.53 \pm 0.26$ \\
ApoB, g/L & $0.90 \pm 0.18$ & $0.89 \pm 0.17$ \\
\hline Dyslipidemic subjects & Male & Female \\
& $\mathrm{n}=519(66.62 \%)$ & $\mathrm{NS}=700(60.71 \%)$ \\
Age, years & $48.8 \pm 14.4$ & $49.6 \pm 15.4$ \\
Cholesterol, mmol/L & $5.58 \pm 1.26$ & $\mathrm{NS}$ \\
Triglycerides, mmol/L & $2.10 \pm 1.41$ & $\mathrm{NS}$ \\
HDL-C, mmol/L & $1.13 \pm 0.33$ & $1.81 \pm 1.07$ \\
LDL-C, mmol/L & $3.57 \pm 1.13$ & $1.62 \pm 0.91$ \\
ApoA1, g/L & $1.39 \pm 0.29$ & $1.45 \pm 0.39$ \\
ApoB, g/L & $1.28 \pm 0.30$ & $3.66 \pm 0.98$ \\
\hline
\end{tabular}

Values are mean \pm SD. NS, not significant.

and the other for serum separation. Samples were transported at $4^{\circ} \mathrm{C}$, when possible by airmail, to the Central Clinical Chemistry Laboratory at the $\mathrm{NIH}$, where lipids were immediately quantified and EDTA samples were stored at $-80^{\circ} \mathrm{C}$. APOE genotyping was performed within 1 month.

\section{DNA extraction and APOE genotyping}

DNA extraction was performed according to the method of Miller et al. (13). APOE genotyping was performed by PCR amplification and subsequent digestion with restriction enzyme Hhal as described by Hixson and Vernier (14).

\section{Lipid analysis}

Serum total cholesterol, high-density lipoprotein-cholesterol (HDL-C) and triglycerides were measured using an enzymatic colorimetric method. Apoliproteins A1 and B were determined by immunoturbidimetry using a Hitachi 911 automated clinical chemistry analyzer (Boehringer Mannheim, Kobe, Japan). The same manufacturer supplied the reagents. The intra- and inter-assay coefficients of variation for these assays were $2.6 \%$ and $2.5 \%$ for total cholesterol, $4.0 \%$ and 4.5\% for HDL-C, $2.0 \%$ and $2.5 \%$ for triglycerides, $1.7 \%$ and $6.6 \%$ for apoA 1 , and $3.2 \%$ and $8.9 \%$ for apoB, respectively.

LDL-C was calculated according to the Friedwald-Fredrickson equation for individuals whose serum triglyceride levels were lower than $4.54 \mathrm{mmol} / \mathrm{L}$.

Different dyslipidemic types were defined based on total cholesterol, LDL-C, HDL-C, and triglyceride levels according to cut-off values specified by the American Expert Panel on Detection, Evaluation and Treatment of High Blood Cholesterol in adults (15)

\section{Statistical analysis}

Student's t-test for independent samples, or the non-parametric Mann-Whitney U-test, when appropriate, was used for comparing the mean values of age and lipid parameters. The assumption of equality of variances was tested using Levene's test. A simple gene-counting method was used to estimate allelic frequencies. Hardy-Weinberg equilibrium and statistical comparisons between populations were performed with a $\chi^{2}$ test.

The association between APOE genotypes and blood lipid levels was determined by computation of specific odds ratios (ORs) for the association of each blood lipid with each of the three $A P O E$ alleles (present vs. absent) in both men and women. The different ORs were adjusted for the different age structure of study subpopulations using logistic regression.

Statistical analyses were performed using SPSS software version 11.0 (SPSS Inc., Chicago, IL, USA) and STATA version 8 for Windows (STATA Corporation, College Station, TX, USA). p-Values less than 0.05 were considered statistically significant.

\section{Results}

\section{Lipid results}

Gender differences in blood lipid levels were observed in normolipidemic subjects: women had higher cholesterol than men, but HDL-C and apoA1 were lower in men than in women.

Dyslipidemic subjects, $66.6 \%$ men and $60.7 \%$ women, showed the same differences as normolipidemic participants: higher cholesterol in women, and higher triglycerides, lower HDL-C and apoA1 in men (Table 1).

Dyslipidemia characterized by hypercholesterolemia was more prevalent in women than in men. On the other hand, isolated hypertriglyceridemia or in association with low HDL-C was more frequent in men.

Dyslipidemic subjects were on average 10 years older than normolipidemics and this was taken into account when calculating the ORs for the association between APOE alleles and lipid concentrations, adjusting for age using logistic regression methods.

\section{Distribution of APOE genotypes}

Table 2 shows the distribution of $A P O E$ genotypes in Hardy-Weinberg equilibrium in all participating regions. A borderline deviation was observed only when $A P O E$ genotypes were considered together $\left(\chi^{2}=6.01 ; p=0.049\right)$. 
Table 2 Frequency of $A P O E$ genotypes and alleles in six Portuguese regions.

\begin{tabular}{|c|c|c|c|c|c|c|c|}
\hline & Porto & Vila Real & Viseu & Lisboa & Portalegre & Faro & Total \\
\hline \multicolumn{8}{|c|}{ Genotype } \\
\hline$\varepsilon 2 / \varepsilon 2$ & 1 & 1 & 1 & 2 & 3 & 0 & $8(0.4 \%)$ \\
\hline$\varepsilon 2 / \varepsilon 3$ & 35 & 25 & 20 & 49 & 18 & 15 & $162(8.9 \%)$ \\
\hline$\varepsilon 2 / \varepsilon 4$ & 1 & 2 & 3 & 5 & 3 & 1 & $15(0.8 \%)$ \\
\hline$\varepsilon 3 / \varepsilon 3$ & 381 & 169 & 154 & 361 & 134 & 126 & $1325(72.4 \%)$ \\
\hline$\varepsilon 3 / \varepsilon 4$ & 69 & 34 & 36 & 90 & 31 & 34 & $294(16.1 \%)$ \\
\hline$\varepsilon 4 / \varepsilon 4$ & 7 & 1 & 6 & 4 & 3 & 4 & $25(1.4 \%)$ \\
\hline Total & 494 & 232 & 220 & 511 & 192 & 180 & 1829 \\
\hline$\chi^{2}$ test & 5.24 & 0.34 & 4.399 & 0.60 & 5.92 & 1.94 & 6.01 \\
\hline$p$ & 0.073 & 0.844 & 0.111 & 0.741 & 0.052 & 0.379 & 0.049 \\
\hline \multicolumn{8}{|l|}{ Allele } \\
\hline$\varepsilon 2$ & 0.038 & 0.058 & 0.060 & 0.057 & 0.070 & 0.045 & 0.053 \\
\hline$\varepsilon 3$ & 0.877 & 0.791 & 0.825 & 0.842 & 0.826 & 0.838 & 0.849 \\
\hline$\varepsilon 4$ & 0.085 & 0.151 & 0.115 & 0.101 & 0.104 & 0.117 & 0.098 \\
\hline
\end{tabular}

The results showed a high $\varepsilon 3$ allele frequency and relatively low $\varepsilon 4$ frequency, with $\varepsilon 2$ the least common allele.

To evaluate the importance of $A P O E$ polymorphisms for dyslipidemias, we compared $A P O E$ genotypes and relative allele frequencies in normolipidemic and dyslipidemic subjects stratified by sex.

In general terms we observed that genotypes with the $\varepsilon 4$ allele were more frequent in dyslipidemic participants. This difference was more pronounced in men than in women $(7.1 \%$ vs. $12.0 \%$ in men; $7.6 \%$ vs. $10.4 \%$ in women).

\section{APOE genotypes and lipids}

In men, the presence of the $\varepsilon 2$ allele was significantly associated with a lower probability of having LDL-C above $4.14 \mathrm{mmol} / \mathrm{L}$ (age-adjusted OR, 0.34; $95 \% \mathrm{Cl}$, $0.15-0.75)$. All other associations were not statistically significant. The presence of the $\varepsilon 3$ allele was not associated with either a lower or higher probability of having any of the dyslipidemias studied.

On the other hand the presence of the $\varepsilon 4$ allele was significantly associated with a higher probability of having $\mathrm{HDL}-\mathrm{C}<1.04 \mathrm{mmol} / \mathrm{L}$ and triglycerides $\geq 1.71 \mathrm{mmol} / \mathrm{L}$ (age-adjusted OR, 2.26; 95\% Cl, 1.41$3.62)$, and a higher probability of having LDL-C above $4.14 \mathrm{mmol} / \mathrm{L}$ (age-adjusted OR, 1.68; 95\% Cl, 1.092.57) and HDL-C below $1.04 \mathrm{mmol} / \mathrm{L}$ (age-adjusted OR, 1.67; $95 \% \mathrm{Cl}, 1.11-2.49)$.

In women, the presence of the $\varepsilon 2$ allele was associated with a significantly lower probability of having cholesterol $\geq 5.17$ and $\leq 6.18 \mathrm{mmol} / \mathrm{L}$ (age-adjusted
OR, 0.62; 95\% Cl, 0.39-0.99), LDL-C $\geq 3.37$ and $\leq 4.14 \mathrm{mmol} / \mathrm{L}$ (age-adjusted OR, $0.49 ; 95 \% \mathrm{Cl}, 0.27-$ 0.87 ) and LDL-C above $4.14 \mathrm{mmol} / \mathrm{L}$ (age-adjusted OR, $0.38 ; 95 \% \mathrm{Cl}, 0.19-0.78$ ). All other associations were not statistically significant for allele $\varepsilon 2$. The presence of allele $\varepsilon 3$ was not associated with either a lower or higher probability of having any of the dyslipidemias studied.

The presence of the $\varepsilon 4$ allele was significantly associated with a higher probability of having LDL-C above $4.14 \mathrm{mmol} / \mathrm{L}$ (age-adjusted OR, 1.79; 95\% Cl, 1.19-2.69) and cholesterol $>6.21 \mathrm{mmol} / \mathrm{L}$ (OR, 1.85: $95 \% \mathrm{Cl}, 1.25-2.74)$. All other associations were not statistically significant for allele $\varepsilon 4$.

Table 3 presents mean values and standard deviation for lipid parameters by sex and by the most prevalent $A P O E$ genotypes.

\section{Discussion}

The allelic frequencies observed in this study are in agreement with those we obtained in another study of the Portuguese population conducted in the Lisbon area under the ApoEurope Project (16). As in almost all populations, the $\varepsilon 3 / \varepsilon 3$ genotype was by far the most frequent $(72.4 \%)$, and the $\varepsilon 3$ allele accounted for the greatest majority of the APOE gene pool (84.9\%) while $\varepsilon 4$ accounted for $9.8 \%$ and $\varepsilon 2$ for $5.3 \%$. As a result of the lower frequencies of the $\varepsilon 4$ and $\varepsilon 2$ alleles, the genotypes $\varepsilon 4 / \varepsilon 4, \varepsilon 2 / \varepsilon 4$ and $\varepsilon 2 / \varepsilon 2$ were relatively rare. We did not find significant differences in

Table 3 Mean values and standard deviation for lipids, apoA1, apoB and age, according to APOE genotype and sex.

\begin{tabular}{|c|c|c|c|c|c|c|}
\hline & \multicolumn{3}{|l|}{ Men } & \multicolumn{3}{|l|}{ Women } \\
\hline & $\varepsilon 2 / \varepsilon 3$ & $\varepsilon 3 / \varepsilon 3$ & $\varepsilon 3 / \varepsilon 4$ & $\varepsilon 2 / \varepsilon 3$ & $\varepsilon 3 / \varepsilon 3$ & $\varepsilon 3 / \varepsilon 4$ \\
\hline Number & 62 & 515 & 128 & 96 & 781 & 157 \\
\hline Total cholesterol, $\mathrm{mmol} / \mathrm{L}$ & $4.95 \pm 1.49$ & $5.00 \pm 1.20$ & $5.31 \pm 1.18$ & $4.64 \pm 1.09$ & $5.21 \pm 1.13$ & $5.36 \pm 1.19$ \\
\hline $\mathrm{HDL}-\mathrm{C}, \mathrm{mmol} / \mathrm{L}$ & $1.24 \pm 0.35$ & $1.19 \pm 0.28$ & $1.11 \pm 0.29$ & $1.47 \pm 0.36$ & $1.46 \pm 0.35$ & $1.45 \pm 0.34$ \\
\hline LDL-C, mmol/L & $3.63 \pm 4.14$ & $3.78 \pm 3.91$ & $4.44 \pm 4.68$ & $2.76 \pm 2.42$ & $3.28 \pm 1.85$ & $3.46 \pm 2.02$ \\
\hline Triglycerides, $\mathrm{mmol} / \mathrm{L}$ & $1.74 \pm 1.13$ & $1.72 \pm 2.06$ & $1.88 \pm 1.33$ & $1.46 \pm 1.16$ & $1.34 \pm 0.74$ & $1.33 \pm 0.72$ \\
\hline ApoA1, g/L & $1.45 \pm 0.27$ & $1.39 \pm 0.26$ & $1.32 \pm 0.26$ & $1.62 \pm 0.33$ & $1.59 \pm 0.31$ & $1.59 \pm 0.28$ \\
\hline ApoB, g/L & $1.03 \pm 0.26$ & $1.14 \pm 0.32$ & $1.25 \pm 0.31$ & $0.95 \pm 0.26$ & $1.15 \pm 0.31$ & $1.20 \pm 0.32$ \\
\hline Age, years & $45.8 \pm 17.2$ & $44.9 \pm 15.9$ & $46.2 \pm 16.6$ & $43.5 \pm 15.2$ & $45.1 \pm 16.3$ & $43.7 \pm 15.9$ \\
\hline
\end{tabular}

$\varepsilon 2 / \varepsilon 2, \varepsilon 2 / \varepsilon 4$ and $\varepsilon 4 / \varepsilon 4$ genotypes were not included in this analysis on account of their low frequencies. 
the distribution of the APOE alleles in the six participating regions of this study.

Worldwide $A P O E$ allele frequencies differ in various geographic regions. In Europe the $\varepsilon 2$ allele shows an increasing gradient from north to south, and the opposite is observed for the $\varepsilon 4$ allele. The prevalence of cardiac atherosclerotic diseases, and cholesterol and triglyceride concentrations also show the latter distribution. The Finnish population has the highest prevalence of $\varepsilon 4(17.8 \%)$, while the Greek (Crete) $(8.5 \%)$ and Portuguese populations $(9.7 \%)$ have the lowest prevalence (16).

In a comparative study organized by Mahley and Rall (17) on $A P O E$ allele frequencies in 16 distinct countries/world regions/ethnic groups, the $\varepsilon 2$ frequency ranged from $4.1 \%$ to $13 \%$ and that of $\varepsilon 4$ from $7.4 \%$ to $29.1 \%$. Our results are closer to regions with the lowest frequencies of $\varepsilon 4$ and $\varepsilon 2$, such as Japan and Singapore. A study in the Moroccan population also found values rather similar to ours: $\varepsilon 4=11 \%$, $\varepsilon 3=84 \%$, and $\varepsilon 2=5 \%(18)$.

When comparing $A P O E$ genotypes and relative allele frequencies in normo- and dyslipidemic subjects, we observed that the frequency of the $\varepsilon 4$ allele was higher in dyslipidemic subjects of both sexes. This was more pronounced in men due to higher frequencies of the $\varepsilon 3 / \varepsilon 4$ and $\varepsilon 4 / \varepsilon 4$ genotypes than in women, whom, on the other hand, had a low frequency of the $\varepsilon 2$ allele due to a much lower number of $\varepsilon 2 / \varepsilon 3$ genotypes.

More detailed analysis of the relationship between lipids and genotypes (Table 3) shows that genotypes with the $\varepsilon 2$ and $\varepsilon 4$ alleles have respectively lower and higher plasma cholesterol levels compared with the $\varepsilon 3 / \varepsilon 3$ subset.

The genotype associated with higher triglyceride and lower HDL-C levels was $\varepsilon 3 / \varepsilon 4$ in men. According to Dallongeville et al. (6), cardiovascular risk due to the $\varepsilon 4$ allele is increased in individuals with the $\varepsilon 3 / \varepsilon 4$ genotype due to elevated levels of triglycerides and lower HDL-C concentrations - this is the characteristic dyslipidemia of the metabolic syndrome. Moreover, as mentioned by Assmann and co-workers, this $\varepsilon 3 / \varepsilon 4$ heterozygosity compared with $\varepsilon 3 / \varepsilon 2$ heterozygosity and $\varepsilon 3 / \varepsilon 3$ homozygosity is accompanied by an earlier age at myocardial infarction (19).

Considering the associations between lipids and $A P O E$ alleles through the relative ORs, we can again confirm the non-association of $\varepsilon 2$ with cholesterol and the association between $\varepsilon 2$ and high triglycerides/low HDL-C, as well as the association between $\varepsilon 4$ and dyslipidemias rich in cholesterol. The numbers expressing these ORs are relatively low, approximately 1 and 2, which is usual in this type of work [see the Framingham Offspring Study (7)].

Dyslipidemias were observed in a high percentage of the subjects studied (over $60 \%$ ). This finding is relevant, as dyslipidemias are an important risk factor for atherosclerotic disorders, which in Portugal result in high mortality and morbidity rates [39\% of verified deaths in $1999,52 \%$ by stroke and $22 \%$ by cardiac heart disease $(12,20)]$.
Moreover the relationship that dyslipidemias have with the pathogenesis of atherosclerosis is extensively documented and its environmental determinants and clinical consequences are recognized (21-34).

According to this scientific evidence, Portuguese health authorities and scientific societies have widely and repeatedly recommended interventions for earlier diagnosis and control of dyslipidemias in the population, recognizing their importance throughout the country (35-37).

In our study, age and sex were associated with increased serum concentrations of the lipids and apolipoproteins quantified, with the exception of HDL-C, which was decreased.

Regarding age, the usual explanations expressed in the literature cannot be excluded: weight gain during adult life, heredity, selective mortality, and probably a decrease in receptor activity $(38,39)$.

In relation to higher triglyceride values in men than in women and low levels of HDL-C, either in isolation or combined, it is possible that these reflect the influence of obesity, hypertension, a sedentary life and other risk factors associated with metabolic syndrome, which are becoming increasingly prevalent in our population, especially in men (20). The increasing prevalence of type 2 diabetes may also be an important cause. In fact, hyperinsulinemia is associated with increased very low-density lipoprotein (VLDL) secretion by the liver, decreased activity of lipoprotein lipase and decreased HDL-C (40).

Hormonal status as a gender-specific factor could also explain some of the lipid differences observed between men and women. The higher cholesterol values observed in women are probably the result of multiple effects of sex hormones on lipoprotein metabolism. The high number of women aged over 45 years in the sample population may explain some of the differences observed in lipid concentrations, due to the importance of menopause.

Returning to the APOE genotypes/allelic frequencies for normo- vs. dyslipidemic subjects, we observed that $\varepsilon 4$, the allele considered the most pathogenic, is more frequent in dyslipidemic than normolipidemic subjects $(4.9 \%$ excess in males; $2.8 \%$ in females). In our opinion, this small excess of $\varepsilon 4$ alleles in the dyslipidemic population studied, together with the low OR values, suggests that $\varepsilon 4$ is not a major factor in explaining the occurrence of dyslipidemias in Portugal.

In fact, we cannot exclude the possibility that important genetic abnormalities may be present that influence dyslipidemias, such as familial hypercholesterolemia, familial defective apoB-100, and type III hyperlipoproteinemia, although these show a low prevalence in populations studied so far. Nevertheless, it is most probable that lipid variations are polygenic and also depend on environmental factors such as lifestyle.

Major changes in lifestyle have taken place in Portugal since the 1960s, in part associated with an inversion of the age pyramid, approaching what is observed in EU countries. 
According to the few nutrition surveys and official aggregate statistics based on commerce and production, during the last four decades, patterns of food intake have changed progressively from a healthy Mediterranean diet to an atherogenic diet, with a considerable increase in the supply and use of meat, dairy products, oils and fats (except olive oil) and added sugars (41). On the other hand, the supply of fish, cereals and vegetables has decreased. Energy supply from fats, which represented only approximately $24.7 \%$ of the total energy intake in the 1960 s, was $34.3 \%$ of the total energy intake in the late 1990s. Animal fat intake increased from $10 \%$ to $14 \%$ of the total energy intake during the same period (41).

It is thought that different dietary patterns in Portuguese regions that may have existed in the past have become attenuated and cannot be easily differentiated today. To the best of our knowledge, only a report from 1988 based on the 1980 national food consumption survey identified two different nutritional profiles in the country. That in the northern regions, north from the Tejo River (Lisbon area excluded) had traditional food intake habits, with an excess of salt and alcoholic beverages. In the other regions, in the south, a higher intake of proteins and animal fats and a lower intake of carbohydrates and alcoholic beverages were observed (42).

Consequently, standardized morbidity and mortality rates for nutrition-related diseases were higher in the north (liver cirrhosis, esophageal cancer, gastric cancer, CVD and stroke), whereas southern regions had lower CVD, colon cancer and breast cancer rates.

Regions considered in this study included Porto, Vila Real and Viseu in the north, where the frequency of CVD is higher than the national average (191.7/ 100,000 per year) and Lisboa, Portalegre and Faro, where CVD is less frequent than the national average (79.9/100,000 per year).

Other lifestyle-related risk factors deserve mention due to their impact on the lipid profile of the population. According to the World Drink Trends Statistics, alcohol consumption is high in Portugal (14 L/capita per year), clearly above the mean of EU countries. The three available National Health Interview Surveys show that approximately $50 \%$ of the population report alcohol consumption. The contribution of wine, beer and spirits is changing, with wine being more frequently used by middle-aged and older people, whereas beer and spirits are increasingly being used by the young (43).

Portugal has the lowest smoking prevalence in Europe. Data from the three National Health Interview Surveys show that the prevalence of daily smoking in men is slowly decreasing $(33.3 \%, 29.2 \%, 29.3 \%$ respectively), but increasing in women $(5.0 \%, 6.5 \%$, $7.9 \%)$. The increased number of female smokers is particularly relevant in younger age groups, while the decrease in men is observed in all age groups except 35-44 years (43).

In Portugal, as in other countries, there is a trend to a progressive increase in the prevalence of obesity and hypertension $(44,45)$.

\section{Acknowledgements}

We are grateful to Drs. Maria Manuel Freitas, Isabel Quinas Guerra, Jorge Soares, Maria Antónia Ceia and Maria Cecília Silva who contributed in Porto, Vila Real, Viseu, Portalegre and Faro to the recruitment of participants and blood collection.

\section{References}

1. Siest G, Pillot T, Regis-Bailly A, Leininger-Muller B, Steinmetz J, Galteau MM, et al. Apolipoprotein E: an important gene and protein to follow in laboratory medicine. Clin Chem 1995;41:1068-86.

2. Mahley RW, Weisgraber KH, Thomas L, Rall SC Jr. Genetic defects in lipoprotein metabolism. Elevation of atherogenic lipoproteins caused by impaired catabolism. J Am Med Assoc 1991;265:78-83.

3. Mahley RW. Apoliporotein E. Cholesterol transport protein with expanding role in cell biology. Science 1988;240:622-30.

4. Gregg RE, Brewer HB Jr. The role of apolipoprotein E and lipoprotein receptors in modulating the in vivo metabolism of apoliprotein B-containing lipoproteins in humans. Clin Chem 1988;34:B28-B32.

5. Kwijft $P$, Maagdenberg AM, Frants RR, Havekes LM. Genetic heterogeneity of apolipoprotein E and its influence on plasma lipid and lipoprotein levels. Hum Mutat 1994;4:178-94.

6. Dallongeville J, Lussier-Cacan S, Davignon J. Modulation of plasma triglycerides levels by apoE phenotype: a meta-analysis. J Lipid Res 1992;33:447-54.

7. Wilson PW, Myers RH, Larson MG, Ordovas JM, Wolf PA, Schaefer EJ. Apolipoprotein E alleles, dyslipidemia, and coronary heart disease. The Framingham Offspring Study. J Am Med Assoc 1994;272:h1666-71.

8. Davignon J, Gregg RE, Sing CF. Apolipoprotein E and atherosclerosis. Atherosclerosis 1988;8:1-21.

9. Franco A, Martinho MC, Martins MC. Estudo prospectivo de lípidos sanguíneos em amostras da população Portuguesa. Arquivos do INSA 1980;IV:263-92.

10. Franco A, Martinho MC, Martins MC. Os lípidos sanguíneos na doença cardíaca isquémica. Arquivos do INSA 1981;Vl:355-79.

11. Martins MC, Rodrigues MO, Gomes MA, Fonseca A, Faleiro LL. Lípidos em crianças e jovens. Um problema de Saúde Pública. Acta Med Port 1995;8:477-83.

12. Direcção Geral da Saúde. DSIA, Divisão de Epidemiologia. Risco de morrer em Portugal. Lisboa: Direcção Geral da Saúde, 1999:29-52.

13. Miller SA, Dykes DD, Polesky HF. A simple salting out procedure for extracting DNA from human nucleated cells. Nucleic Acids Res 1988;16:1215.

14. Hixson JE, Vernier DT. Restriction isotyping of human apolipoprotein $E$ by gene amplification and cleavage with Hhal. J Lipid Res 1990;31:545-8.

15. Executive Summary of the Third Report of the National Cholesterol Education Program (NCEP) Expert Panel on Detection, Evaluation and Treatment of High Blood Cholesterol in Adults (Adult Treatment Panel III). J Am Med Assoc 2001;285:2486-97.

16. Schiele F, De Bacquer D, Vincent-Viry M, Beisiegel U, Ehnholm C, Evans A, et al. Apolipoprotein E serum concentration and polymorphism in six European countries: the ApoEurope Project. Atherosclerosis 2000;152: 475-88.

17. Mahley RW, Rall SC Jr. Type III hyperlipoproteinemia (dysbetalipoproteinemia): the role of apolipoprotein $\mathrm{E}$ in normal and abnormal lipoprotein metabolism. In: Scri- 
ver CR, Beaudet AL, Sly WS, Valle D, editors. The metabolic and molecular bases of inherited disease. New York: McGraw-Hill, 1995:1953-80.

18. Lahlali-Kacemi N, Bamon Y, Guedira A, Hassani M, Visvikis $S$, Siest $G$, et al. Polymorphisme de I'apolipoprotéine $E$ dans une population Morocaine: fréquence allélique et relation avec les paramètres lipidiques plasmatiques. Ann Biol Clin 2002;60:73-8.

19. Lenzen HJ, Assmann G, Buchwaisky R, Schulte H. Association of apolipoprotein $\mathrm{E}$ polymorphism, low-density lipoprotein cholesterol, and coronary artery disease. Clin Chem 1986;32:778-81.

20. Ministério da Saúde. Direcção Geral de Saúde. Ganhos de Saúde em Portugal: Relatório do Director Geral e Alto-Comissário da Saúde. Lisboa: Direcção Geral da Saúde, 2002:113-6.

21. Galton DJ. Genetic determinants of atherosclerosis related dyslipidemias and their clinical implications. Clin Chim Acta 1997;257:181-97.

22. Brown BG, Zhao XQ, Sacco DE, Albers JJ. Lipid lowering and plaque regression. New insights into prevention of plaque disruption and clinical events in coronary disease. Circulation 1993;87:1781-91.

23. Lindenstrom E, Boysen G, Nyboe J. Influence of total cholesterol, high density lipoprotein cholesterol, and triglycerides on risk of cerebrovascular disease: the Copenhagen City Heart Study. Br Med J 1994;309:11-5.

24. Pedersen TR, Kjekshus J, Berg K, Haghfelt T, Faergeman $\mathrm{O}$, Faergeman $\mathrm{G}$, et al. Randomised trial of cholesterol lowering in 4444 patients with coronary heart disease: the Scandinavian Simvastatin Survival Study (4S). Lancet 1994;344:1383-9.

25. Assmann G, Gotto AM Jr, Paoletti R. The hypertriglyceridemias: risk and management. Am J Cardiol 1991;68: $1 \mathrm{~A}-4 \mathrm{~A}$.

26. Schachter M. The pathogenesis of atherosclerosis. Int J Cardiol 1997;62:3-7.

27. Libby P, Sukhova G, Lee RT, Liao JK. Molecular biology of atherosclerosis. Int J Cardiol 19971;62(Suppl 2):S23-9.

28. Hofker M. Lipoxygenases at the heart of atherosclerosis susceptibility. Eur J Hum Genet 2004;12:601-2.

29. Grundy SM. Inflammation, hypertension, and the metabolic syndrome [editorial]. J Am Med Assoc 2003;290: 3000-2.

30. Ross R. Atherosclerosis: an inflammatory disease. N Engl J Med 1999;340:115-26
31. Ross R. The pathogenesis of atherosclerosis: a perspective for the 1990s. Nature 1993;362:801-8.

32. Shepherd J, Krauss RM. Pathophysiology of triglyceriderich particles. A. Metabolism of triglyceride-rich particles. Am J Cardiol 1991;68:5A-7A.

33. Poulter NR. High-density lipoprotein and coronary artery disease: the fibrate renaissance - introduction. Am J Cardiol 2001;88:1N-2N.

34. Libby $P$. Managing the risk of atherosclerosis: the role of high-density lipoprotein. Am J Cardiol 2001;88:3N-8N.

35. Ministério da Saúde, Direcção Geral da Saúde. Programa Nacional de Prevenção e Controlo das DCV - Circular Normativa da Direcção Geral de Saúde 05/09/03. Lisboa: Direcção Geral da Saúde, 2003.

36. Silva PM, Silva JM, Gil VM. Prevenção cardiovascular: recomendações para a abordagem do risco vascular associado às dislipidémias. Rev Port Cardiol 2002;21: 1201-9.

37. Sousa JC, Pinto DS. Valores laboratoriais do estudo lipídico e risco vascular. Rev Fac Med Lisboa Ser III 2003; 8:75-81.

38. Alaupovic P, McConathy WJ, Fesmire J, Tavella M, Bard JM. Profiles of apolipoproteins and apolipoprotein Bcontaining lipoprotein particles in dyslipoproteinemias. Clin Chem 1988;34:B13-B27.

39. Schaefer EJ, McNamara JR, Genest J, Ordovas JM. Genetics and abnormalities in metabolism of lipoproteins. Clin Chem 1988;34:B9-B12.

40. Patsch W, Franz S, Shonfeld G. Role of insulin in lipoprotein secretion by cultured rat hepatocytes. J Clin Invest 1983;71:1161-74.

41. Amorim Cruz JA. A evolução dos consumos alimentares em Portugal nas últimas 4 décadas. Rev Port Nutr 1999;9:5-15.

42. Amorim Cruz JA. Alimentação e Saúde em Portugal: estudo ecológico com apresentação de perfis nutricionais distritais. Edit INDC, 1988.

43. Graça MJ, Matias Dias C. The National Health Interview Surveys. History, methods and results. Lisboa: Instituto Nacional de Saúde, 2002.

44. Ministério da Saúde. Inquérito Nacional de Saúde 1998/ 99. INSA-ONSA, 2001.

45. Carmo I. Obesidade: epidemia global. Rev Fac Med Lisboa Ser III 2001;6(Suppl 1):39-46.

Received February 21, 2005, accepted July 19, 2005 